\title{
The application of science to the management of Atlantic salmon (Salmo salar): integration across scales
}

\author{
John D. Armstrong, James W.A. Grant, Harvey L. Forsgren, Kurt D. Fausch, \\ Richard M. DeGraaf, lan A. Fleming, Terry D. Prowse, and Isaac J. Schlosser
}

\begin{abstract}
The need for integration across spatial and temporal scales in applying science to the management of Atlantic salmon is considered. The factors that are currently believed to affect the production of anadromous adult Atlantic salmon (synthesized from recent reviews) are arranged in a hierarchy in which any given process overrides those processes at lower levels. There is not a good correlation between levels in the process hierarchy and levels in hierarchies of scale. This demonstrates the importance of integrating across scales in identifying the optimum foci for targeting management action. It is not possible to generalize on the need for integration across scales within management plans. This is because of the complex ecology of salmon, the broad range of characteristics of the systems of which they are a part, and the fact that both local scale and broad scale management can have broad scale effects. Many uncertainties remain regarding the large-scale components of the ecology of salmon, the way that small-scale mechanisms interact with life histories, and the way that different factors interact to limit production of fish. When more is understood of these processes, it is likely that generalized rules might be developed to predict the management requirements for stream systems. In the meantime, it is essential that there is good integration among managers working at different scales and it is important that management systems operating at all spatial scales include highcalibre expertise to compensate for the present paucity of general rules.
\end{abstract}

Résumé : On examine la nécessité d'une intégration suivant les échelles spatiales et temporelles dans les applications des résultats scientifiques à la gestion du saumon atlantique. Les facteurs qui, croit-on actuellement, influent sur la production du saumon atlantique anadrome adulte (selon une synthèse des études récentes) sont arrangés suivant une hiérarchie dans laquelle tout processus donné prévaut sur les processus des niveaux inférieurs. Il n'y a pas une bonne corrélation entre les niveaux dans la hiérarchie de processus et les niveaux dans les hiérarchies d'échelle. Cela montre l'importance d'une intégration suivant les échelles pour établir les cibles optimales des mesures de gestion. Il n'est pas possible de faire des généralisations en ce qui concerne la nécessité de l'intégration suivant les échelles dans les plans de gestion en raison de l'écologie complexe du saumon, du vaste éventail de caractéristiques des systèmes dont il fait partie et du fait que la gestion à l'échelle locale et la gestion à plus grande échelle peuvent toutes deux avoir des effets à grande échelle. Il existe encore de nombreuses incertitudes quant aux composantes à grande échelle de l'écologie du saumon, à la manière dont interagissent avec les cycles vitaux les mécanismes à petite échelle, et à la manière dont divers facteurs interagissent pour limiter la production de poisson. Quand on en saura davantage sur ces processus, on pourra probablement élaborer des règles générales pour prévoir les exigences en matière de gestion des systèmes fluviaux. Dans l'intervalle, il est essentiel qu'il existe une bonne intégration entre les gestionnaires qui travaillent à différentes échelles, et il est important que les systèmes de gestion fonctionnant à toutes les échelles spatiales soient assortis d'une grande expertise pour que soit compensé le manque actuel de règles générales.

[Traduit par la Rédaction]

Received November 7, 1997. Accepted September 20, 1998.

J14293

J.D. Armstrong. Freshwater Fisheries Laboratory, Faskally, Pitlochry, Perthshire, Scotland, PH16 5LB, U.K.

J.W.A. Grant. Department of Biology, Concordia University, 1455 de Maisonneuve Blvd. W., Montreal, QC H3G 1M8, Canada.

H.L. Forsgren. USDA Forest Service, P.O. Box 96090, Washington, DC 20090-6090, U.S.A.

K.D. Fausch. Department of Fishery and Wildlife Biology, Colorado State University, Ft. Collins, CO 80523, U.S.A.

R.M. DeGraaf. Northeast Forest Experimental Research Station, USDA Forest Service, University of Massachusetts, Holdsworth Hall, Amherst, MA 01003, U.S.A.

I.A. Fleming. Norwegian Institute of Nature Research, Tungasletta 2, N-7005 Trondheim, Norway.

T.D. Prowse. National Water Research Institute, Environment Canada, 11 Innovation Blvd., Saskatoon, SK S7N 3H5, Canada. I.J. Schlosser. Department of Biology, University of North Dakota, P.O. Box 9019, Grand Forks, ND 58202, U.S.A. 


\section{Introduction}

This overview is one of a series of papers that consider integration across scales in relation to the biology of Atlantic salmon, Salmo salar L. The paper synthesizes the conclusions of other papers in the series, together with additional information, to evaluate the importance of integration across scales in applying scientific knowledge to the management of Atlantic salmon.

The two scales of physical and biological processes generally considered by ecologists are space and time. A fundamental characteristic of these scales is that when viewed as hierarchical continua, smaller-scale systems develop within the constraints set by the large-scale system (Rabeni and Sowa 1996; Lewis et al. 1996). Considering space and time as related to systems inhabited by salmonid fishes (e.g., Frissell et al. 1986), large scales, such as evolutionary time and catchment geomorphology, are at high levels of the hierarchy whereas small-scale processes, such as local sediment dynamics and development rates of individual fish, are at low levels.

Scale hierarchies have been viewed as useful models to focus aspects of the management of fish. For example, by applying scale hierarchies in the evaluation of the restoration of certain populations of fish in the Great Lakes, it was concluded that integration across scales is essential (Imhof et al. 1996; Lewis et al. 1996) and that large-scale processes should be considered preferentially in the first instance (Rabeni and Sowa 1996). A cautionary note was also sounded: that to recommend the management of large-scale processes may be arrogant because of ecosystem complexities and conflicts with other user groups (White 1996).

A main aim of this paper is to consider, for managing populations of Atlantic salmon, whether it is appropriate to focus on processes at any particular scale or whether it is appropriate to integrate across scales. If integration across scales is appropriate, then we aim also to establish what ranges of scales are most relevant and what might be the most suitable human resource structures for applying scientific principles to management over a range of scales. The paper comprises six parts in addition to the Introduction: (1) The general aims of managers of Atlantic salmon are outlined in relation to the general biological characteristics of the fish. (2) A general hierarchical structure relating the processes and factors that influence the numbers of salmon available to fisheries is developed. The principle of this process hierarchy is that processes at high levels override those at lower levels and so might be considered the preferred target for management action. The process hierarchy is constructed without reference to the scale hierarchies described earlier. (3) The process hierarchy is compared with scale hierarchies to ascertain whether there are good correlations between levels of processes and levels of spatial and temporal scales. If the correlation is good then, logically, it would be reasonable to conclude that management should, ideally, target the scales that correspond with processes high up the process hierarchy. (4) The extent of our knowledge of the biology of Atlantic salmon across the range of appropriate scales is assessed. (5) Drawing on the findings of the third and fourth sections, the scope for applying general sciencebased principles to the management of salmon is assessed.
(6) The human organization framework needed to apply science to the management of Atlantic salmon effectively over the appropriate range of scales is considered.

\section{A summary of management options}

The requirements for management of Atlantic salmon depend on the life history (Hutchings 1998) of the fish. Salmon spawn in nests in fresh water. Young salmon ("alevins") emerge from the eggs and survive predominantly on a yolk-sac until they learn to feed on exogenous food (when they may be termed "fry"), which comprises mainly invertebrate larvae. As the salmon use up their yolk sacs and disperse from the redd they become known as "parr." They grow in fresh water for several years and may mature as parr. A proportion of the population, which may include previously mature and juvenile individual fish, is anadromous and changes from the freshwater form to the pelagic marine form (becoming "smolts") and migrates to sea during spring. Salmon may stay at sea from just over one year to several years before returning to fresh water to spawn.

The main management objectives in optimizing the success of fisheries are, first, to ensure that the numbers and quality of smolts produced by a spawning population, or spawning unit, of salmon are optimized. Secondly, to maximize the survival of smolts to adults. Thirdly, to regulate the proportions of adults caught by different fisheries and to ensure that a sufficient number of salmon returns to spawn. These management objectives might, in part, be attained by manipulating the chemical, physical and biological processes that affect salmon.

\section{A hierarchy of processes affecting the production of anadromous adult salmon}

The production of anadromous Atlantic salmon is influenced by a wide range of factors including chemical, physical, and biological processes. These processes and factors (which will be generically termed processes for convenience hereafter) can be arranged in a hierarchy of influence. Within this framework, processes on any given tier override those on lower tiers. The process hierarchy will vary between stocks of salmon, so here a general example is considered (Fig. 1) that includes many of the processes that affect many stocks in many rivers. The highest level processes are geology, climate, and those chemical changes that may influence geology and (or) climate. These processes may interact with one another. For example, change in chemical composition of the atmosphere, including perhaps anthropogenic oxidation of fossil fuels, may change global climate, while global climate, through its effect on temperature, may affect the need for humans to burn organic material. Geological processes, such as plate tectonic uplift and soil genesis, are critical in determining many physical characteristics of streams and rivers (Frissel et al. 1986).

The second tier includes geomorphology, determined by the interaction of geological processes and climate in the past. This basic "natural" feature influences two high-level anthropogenic processes: land use and introductions of fish species. In this context, land use includes a broad range of factors such as agriculture and in-river engineering works. Due to lag times, the climate that determined geomorphol- 
Fig. 1. A hierarchy of processes and factors affecting the production of anadromous Atlantic salmon. Processes on each tier override those processes on lower tiers. Arrows indicate interactions and move from the affecting factor to the effected factor. The processes on adjacent tiers may be linked by lagtimes and genetics (see text for details).

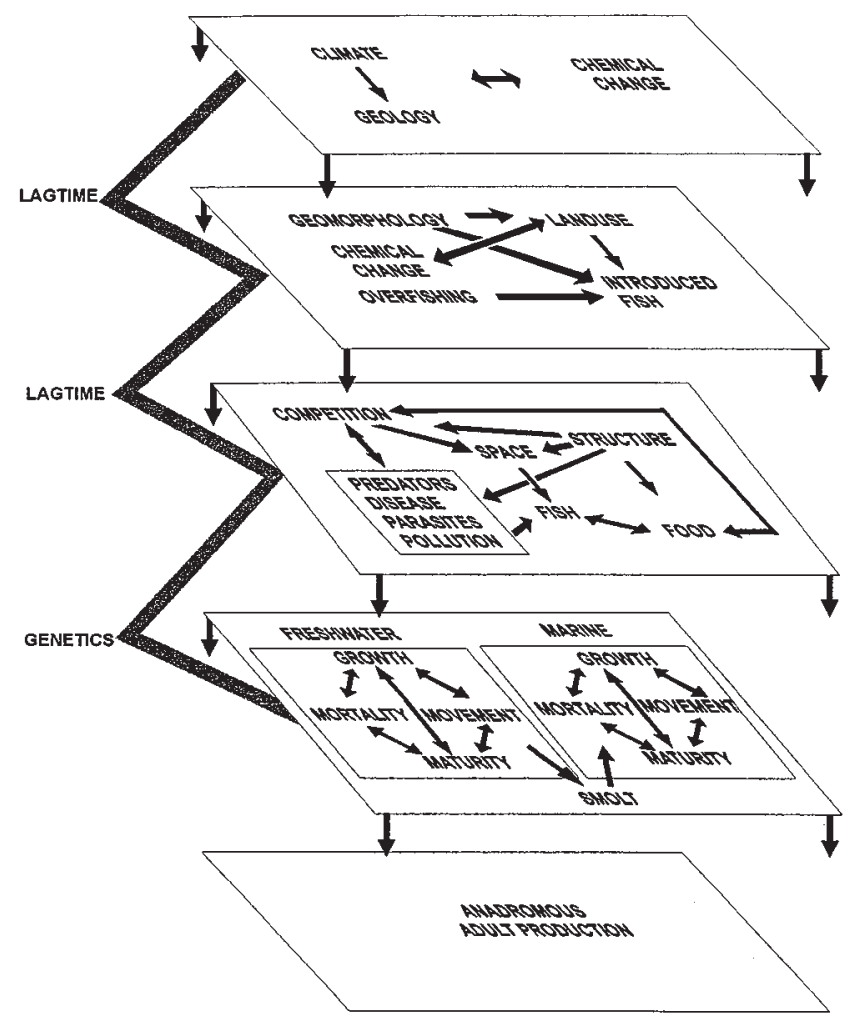

ogy might be quite different from that which now influences the way land is used. Similarly, lag times in the responses of river systems may result in rivers today being influenced by pollution and land use practices of past decades and millennia. Chemical changes, both "natural" and anthropogenic, that do not affect climate may be included on the second tier. The combination of processes on this tier within a stream or river catchment creates the environment for spawning and production of smolts. Similar principles apply in the oceans. Historically, geotectonics determined the positions of the continental masses and the forms of the ocean basins. Current climate determines the positions of the ocean fronts, which may affect the marine survival and growth of salmon (Friedland 1998). Ultimately, climate affects the distribution and abundance of non-salmonid fish stocks and this will influence the use of the sea by man and hence interactions between salmon populations and fisheries for other species. Geomorphology, through the development of inlets and fjords, underpins the distribution of introduced farmed salmonid fishes that interact with wild stocks of salmon (Gross 1998; Youngson and Verspoor 1998).

The third tier (Fig. 1) includes the fundamental local processes that affect individual salmon at any point in time. Many of the processes apply to spawning fish, juveniles growing in the river, and maturing salmon in the sea. Fish need suitable space (Allen 1969; Grant et al. 1998), may need suitable food (not in the case of eggs and returning adult fish), are affected by competitors (of the same and different species (Fausch 1998)), may be at risk from predation (Mather 1998), disease and parasites (Bakke and Harris 1998), and may be influenced by water quality. Spawning usually occurs only in areas of specific substrate and water flow conditions (Beland et al. 1982; Gibson 1993; Fleming 1996). As salmon fry and parr grow, their requirements change: they use deeper water, rougher substrate, and increased water velocities (Heggenes 1990). Habitat requirements may vary throughout the year, particularly in streams where ice cover is extensive in winter (Cunjak 1996).

The physical conditions available for spawning, rearing of juveniles, and survival of adults in rivers depend principally on geomorphology and the use of land in the river catchment, both by humans and the terrestrial communities of plants and animals. In addition to these factors, the aquatic community (including salmon, their predators, competitors, and prey) is affected by lagtimes such as occur with climatic influence. The fish faunas of many northern rivers remain impoverished in terms of species diversity following the last ice age so that there may be few species of fishes competing with salmon (Welcomme 1992; Wheeler and Maitland 1973). Artificial stocking can result in an acceleration of the process of recolonization and the introduction of non-native ("exotic") species of fishes. In effect, this may constitute anthropogenic manipulation of lagtime.

While the top three tiers include the factors that influence individual fish, the fourth tier includes the responses of fish to those processes. Local processes in the third tier can affect individual growth, mortality, age of maturation, tendency to move, and tendency to migrate to sea: these are the main components of life histories (Hutchings 1998). These responses may be interlinked since growth and mortality are often related (Beverton and Holt 1959) as are movement and maturity (Jonsson and Jonsson 1993) and growth and maturity (Metcalfe 1998). The scope within which salmon respond to any set of environmental circumstances is limited by their genetic constitution and so is influenced by past responses. In this way the genes of fish, together with the time for natural selection to occur, cause a lag in response. From the point of view of the management of salmon populations, the nature of the response at this fourth tier level is crucial since it determines the proportion of the population that migrates to sea and returns as the large adult fish of interest to fishermen.

\section{Scales within the process hierarchy}

Salmon occupy various ranges of scales of time and space at different stages of their life cycle (e.g., McCormick et al. 1998). Eggs are deposited within redds covering a few metres and incubate in a few months. Fry and young parr probably disperse for a period of weeks and over a range of the order of ca.1-1000 m. Parr occur within rivers for up to ca. $5 \mathrm{yr}$ and during that time may range over a few metres to at least several kilometres (Erkinaro 1995). The smolt run occurs actively for several months and over most of the length of many rivers. Movements at sea may be over thousands of kilometres and over several years and the returning 
adults may stay within the river for over a year prior to spawning. When plotted together, the temporal and spatial scales encompassed by the salmon life cycle include a wide range of the possible combinations within broad limits (Fig. 2). In terms of space utilization, the salmon life history occupies a large proportion of the total scale. On the temporal scale, the life-cycle is short compared with the total extent of geological time. However, the processes of stock differentiation, the evolution of salmon and the influence of past climatic, geological, and anthropogenic processes (Fig. 1) extend the temporal scale considerably.

Since the third tier of the process hierarchy includes local processes and these are overridden by the processes in the top two tiers, it may appear that management should focus on large-scale processes. But this is not strictly true, because the top two tiers include some processes with immediate actions on local scales and others that act over large scales. Because anadromous salmon move over large distances, small-scale local processes may affect a large proportion of the population. For example, local pollution may affect every smolt leaving a river, and a single weir may impair every adult fish returning from sea. Because a large proportion of a salmon population may be clumped at certain times, for example when spawning in key local areas determined by geology of a river catchment, small-scale processes in those areas may severely affect the population. Large-scale processes may also, in some cases, have an overriding influence on salmon production. For example, human activities may cause widespread eutrophication, climate may result in a long summer growing season, and geology may result in a boulder-strewn river.

It is evident that factors operating over a wide range of scales may have influences on the survival and prosperity of an individual fish at any one point in time. For example, on the spatial scale, the abilities of salmon to utilize systems of olfactory cues may enable them both to home accurately as adults over thousands of kilometres (Quinn and Dittman 1992) and to manoeuvre as parr within a few centimetres in the stream to obtain the best feeding sites (Braithwaite et al. 1996). Hence, effects of pollutants on olfactory physiology may interfere with behavior and ecology over a broad range of scales. Temporally, at one extreme factors that influence evolution of the genome and geomorphological scales extend over thousands of years, while at the other extreme, the escape response of individual fish from predators operates at the scale of milliseconds. Both scales of process may effectively determine, at an instant, whether or not a salmon escapes from a predator, finds suitable cover, and survives.

Appreciating the large range of scales utilized and the vast areas of space that may be used during the lifetime of individual salmon is of fundamental importance for devising suitable research and management programmes.

\section{Scale of research}

In general, much is known of the small-scale processes whereas little is understood of the large-scale processes that influence production of salmon. To give some examples. While the nature and mechanisms of local site attachment are quite well understood (Stradmeyer and Thorpe 1987; Braithwaite et al. 1996; Armstrong et al. 1994, 1997) little is
Fig. 2. Stages of the life cycle of Atlantic salmon in relation to scales of space and time. Kelts refers to the period during which adult anadromous salmon remain in the river after spawning; river adults refers to the period during which anadromous adult salmon are in the river prior to spawning; marine adults refers to the period when adult salmon are at sea.

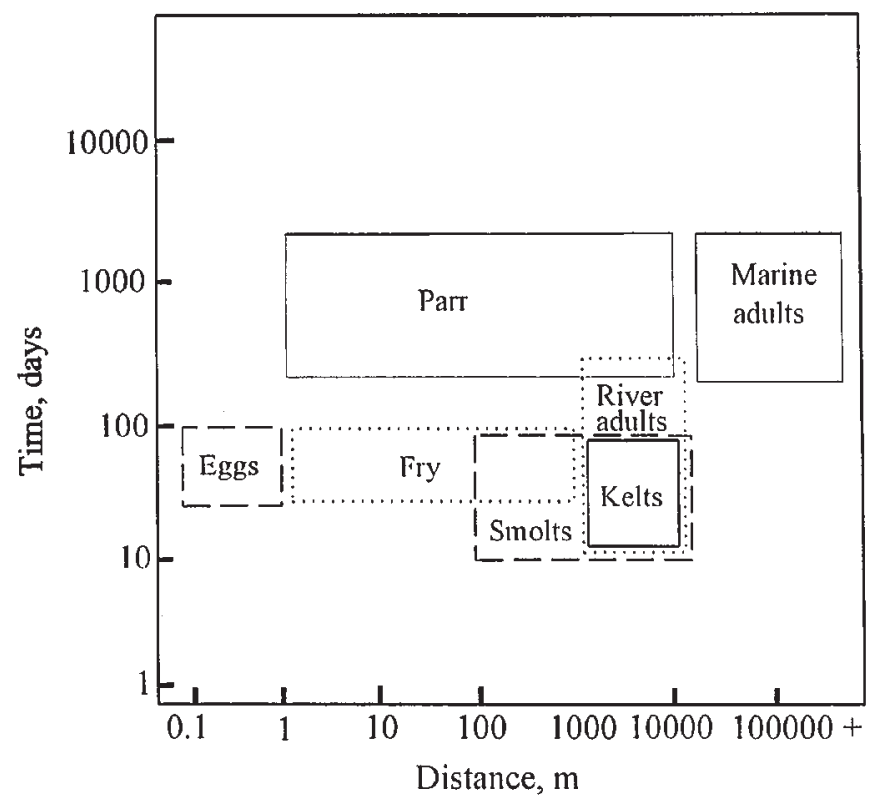

known of the mechanisms underlying large-scale movements of salmon parr (Gowan et al. 1994). Similarly, territoriality of emergent fry appears to be quite well understood (Gustaffson-Greenwood and Moring 1990) but there is little information on the extent and nature of fry dispersal in the wild. The nature of local movements of overwintering salmonids is becoming clearer (Heggenes et al. 1993), but little is known of the larger-scale movements that may be of overriding importance (Cunjak 1996; Cunjak et al. 1998). Consequently, it is difficult or impossible to model relationships between geomorphology, which determines the presence of special (and often limited) habitats that are crucial for spawning and perhaps over wintering, and the dynamics of populations. Very little is known of the biology of the movements of Atlantic salmon at the largest spatial scales during marine migration.

Extrapolation to life history models of large-scale population processes from small-scale artificial systems should be cautious. Information on behavioral and physiological mechanisms underlying growth and maturity forms an important advance in our understanding of the mechanisms that may control life history processes (Metcalfe 1998), but we generally have little idea of how they act in nature. For example, direct links have been established between metabolic rate, early emergence, dominance, and age of smolting in cultured salmon (Metcalfe et al. 1995). However, it is not clear whether similar correlations apply consistently in natural streams where variations in dominance of fry early in life might act primarily to encourage dispersal from the redd. Behavior of salmon does not necessarily conform with the assumptions implicit in simple ecological models such as the Ideal Free Distribution (Armstrong et al. 1997). Therefore, 
more information is needed to understand how the distributions of salmon are influenced by the distributions of the resources they use and by interactions between individual fish.

Genetic responses constitute a lagtime between environmental conditions of the past and the present. As human influence on the environment results in rapid change, and manipulations of fish populations (for example by stocking) affect their gene pools, there is no certainty that populations are well-adapted to the habitats in which they live. This may greatly complicate the process of modelling the ecology of the fish since the normal null assumption that behavior is adapted to the local environment may be invalid. For example, the optimal response of salmon parr to de-watering appears to differ depending on whether it is to long-term drought or to short-term reduction in water flow (Armstrong et al. 1998). Hence, exposure of a population to a series of reductions in flow due to anthropogenic de-watering may reduce the ability of fish in subsequent generations to react appropriately to natural drought.

In general, our understanding of Atlantic salmon on small scales is increasing rapidly but we are only gradually expanding that understanding to encompass the larger-scale processes that impinge on the biology of the fish. This is being facilitated by the development of new techniques such as the application of miniature electronic tags for extending spatial scales of measurements (Prentice et al. 1990; Armstrong et al. 1996) and genetic tags (Nielsen 1998) for extending the temporal scale. Another advance in our knowledge arises from the continually increasing period over which natural populations of Atlantic salmon have been monitored. Given the many uncertainties in the base information available for developing policy, adaptive management, the process of monitoring current management policy to use it as a natural experiment (Lee 1993), is strongly advocated (Naiman et al. 1995). Failure to monitor the success or failure of management measures is a serious waste of an important opportunity to improve policy.

\section{Application of science to management}

From the preceding sections it is evident that in considering the application of science to management of Atlantic salmon it is necessary to integrate across scales. This conclusion is important because management processes, capabilities, and responsibilities may also vary across scales. For example, maintaining a local area that is crucial for salmon spawning may (in some countries) be within the powers of the local landowner, whereas controlling diffuse pollution may be the responsibility of a Government Agency. At a still larger scale, international organizations (NASCO and ICES) manage stocks of salmon on the high seas, which may include populations of fish from a number of different countries. Hence, to develop management plans that integrate the necessary management agents it is essential to understand what ranges of scales should be included. To be most effective, such plans should have general applicability so that simple protocols might form the basis for practical global policies. Unfortunately, the development of general guidelines for integrating across scales of management is confounded by the facts that river catchments that support Atlantic salmon are highly complex and vary greatly in size, and our understanding of the biology and ecology of the fish is incomplete.

This is illustrated by considering the management of smolt production. To increase the production of smolts in a river it is necessary to understand what is (are) the limiting factor(s). Cohorts may be limited by insufficient spawning fish, insufficient spawning areas, or a habitat bottleneck in the first summer after hatching (Armstrong 1997). During the development stage of parr there may be a limitation of space for foraging (Grant and Kramer 1990), refugia, or food (Poff and Huryn 1998). Over-winter there may be a bottleneck due either to inadequate habitat (Cunjak 1996; Mason 1978; Cunjak et al. 1998) or disproportionate mortality relative to growth (Armstrong 1997). Catastrophic or annual habitat changes such as drought (Elliott 1994) may limit cohort size. Other factors that occasionally or regularly may limit production of smolts are poor water quality, predators (Mather 1998), parasites, or disease (Bakke and Harris 1998). As well as influencing numbers of smolts produced, some environmental factors, such as temperature (McCormick et al. 1998), may influence the quality of those smolts and so the chances of their returning as adults to the fishery.

The various factors that may potentially limit the production of smolts relate to various scales. For example, food may be limiting due to the eutrophic state of the catchment (a large-scale process) whereas overwintering survival may be limiting due to the extent of suitable local refuges (which may be a relatively small-scale process). In some instances, large- and small-scale processes may be closely linked. For example, spawning activity may be limited to a few key areas (Schlosser and Angermeier 1995; Fleming 1998) that result from interactions between fluvial mechanics and the underlying geology. These areas may themselves vary in position over time as the river channel progressively moves. This presents an interesting interaction between scales: the large-scale process results in a need for careful management at a very local scale. There are still further scale implications for management strategies of such local "hot spots." Sampling effort should be deployed over a sufficiently broad scale at sufficient resolution to identify sites of key importance and at a sufficient spatial scale to monitor changes in their positions. Because the key factor(s) that limit the production of smolts may vary among river systems, or streams within a river system, it is not possible to derive one single overriding management action strategy.

A further potential problem of advocating generalized policies is the possibility of variations in the trade-offs between the multiple outcomes of a single policy. For example, a single catchment-scale policy, the encouragement of bankside vegetation, may have potential benefits, for example in stabilizing soils, but potential negative effects in accelerating growth rates of fish, through the introduction of invertebrate food, and by encouraging production of competitors of salmon, such as brown trout, Salmo trutta L. An increase in food supply produces only a modest increase in the standing stock of salmon; unfortunately, most of the increase in standing stock is caused by an increase in growth rate rather than an increase in the survival rate of parr (Grant et al. 1998). Consequently, depending on competition between cohorts, numbers of adults produced annually may not vary appreciably. In some instances changes in growth may lead to 
an increase in overwinter survival but may also result in increased incidence of maturity of male salmon as parr (Metcalfe 1998). This in turn may reduce the proportion of anadromous salmon since mature male salmon may have a high mortality and may stay in the river. There may also be a connection between slow growth and a tendency for salmon to return as multi-sea-winter fish early in the year (a resource of exceptionally high value in some countries) (Shearer 1990). If this connection is to some extent under environmental (rather than genetic) influence then modification of growth processes may have serious effects for fisheries. Finally, growth rates early in life may influence the numbers and sizes of eggs produced by anadromous adults (Jonsson et al. 1996).

The importance of choosing appropriate scales for studying population processes (Folt et al. 1998) can equally be applied to the consideration of such processes in management strategies. Management actions at a local scale can often make the most profound improvements to fisheries. For example, the removal of obstructions to upstream migrant salmon can open up large areas of catchments for the production of juveniles. Similarly, the removal of point sources of pollution may improve a large area of the catchment downstream. Salmon are particularly vulnerable as smolts leaving river systems. Damage by predators may be disproportionately intense at specific locations during the smolt run, for example, where fish are funnelled through hydroelectric-related structures. Hence, predator control policies (if pursued) should perhaps focus in the first instance at this small temporal and spatial scale.

At present there appear to be few simple and general rules relating the scales of the biology of salmon to management of the fish: each production system should be considered independently. In the past, much effort has been invested in the development of simple models (for some examples, see Fausch et al. 1988) that have not identified clearly the importance of hierarchical, rather than simultaneous, limiting factors. A clearer framework for relating scales of science and management may emerge in the future when greater emphasis is placed on classifying systems according to appropriate general characteristics, and then applying management models appropriate to the type. For example, it may emerge that models for predicting the abundance of parr are useful only in those rivers where spawning habitat is widely dispersed throughout the system. In this sense, a hierarchy of management priorities (e.g., first assess distribution of spawning areas, then apply the habitat model appropriate to the limiting factors) would be useful. Categorizing river systems and quantifying the scale of different impacting factors (Elliott et al. 1998) are important steps in rationalizing the management of salmon.

\section{Promoting the application of science- based management concepts}

We have focused on the identification of practical applications for the science-based concepts. However, we also recognize the difference between knowing how to apply concepts and actually getting them applied. Although there is much we do not know about Atlantic salmon, often more is known than is used to manage the species effectively.
If the application of science-based concepts in management of Atlantic salmon is to be increased, scientists will have to take an active role, as emphasized by Naiman et al. (1995). Figure 3 illustrates one model that summarizes an approach to maximizing the application of science in management decisions. This model suggests there are multiple paths that scientific findings may take to be adopted and used by managers. Several features are critical to the utility of the model.

First, at the foundation of the model, is an awareness on the part of scientists of the factors that motivate or are relevant to managers. The term "manager" is broadly used to describe the wide variety of individuals, groups, and organizations whose decisions affect Atlantic salmon. Managers therefore may range in scale from local land owners to international governmental organizations.

Sources of "motivation" are unique to different managers and are dynamic over time and (or) space. In general, people and organizations are motivated by those things that provide them value. Science that helps enhance management efficiency (e.g., reduce cost), increase management effectiveness (e.g., improve results), maintain or enhance management flexibility (e.g., options), meet legal or policy requirements, or ameliorate controversy is likely to be viewed as valuable, adopted, and used.

Second, the model requires explicit identification of relevant research findings and applications. This step is characterized as a "lens" in the diagram. The lens represents identification and consideration of the values, needs, and concerns of the intended audience. The lens is not in place to "muzzle" the scientist, modify research findings, or withhold "bad news." The purpose of passing the body of science through the lens is to focus and clarify the message enhancing the utility of the information to the recipient or presenting the information in the context of the intended audience and therefore increasing the probability of its use. This active role is in contrast to the more traditional approach of completing research and expecting managers to discover its usefulness. The concept is also useful in the design of researchable questions that will be relevant to managers - but perhaps not as narrowly as managementdirected research issues may sometimes be framed. Because "relevance" is dynamic, this sensing of values, needs, and concerns must be continuous.

Third, the model suggests the importance of making conscious decisions about who is best suited to convey the science information, fulfilling the role of credible liaison. Credibility is determined by the recipient of the information. In some cases this will be the scientists themselves. In other cases it will be an intermediary that is respected by both the scientists and the target audience. In still other situations, the most effective person to convey the information will be a peer from within the target audience. Credible liaisons are generally familiar with the target audience, can see the world through their "lens," and help promote understanding of that particular audience's values, needs, and concerns within the science community.

Finally, as noted previously, the model recognizes that scientific findings may become valuable to managers only after being relayed by other people or organizations that have influence with them. In the model these "relays" are 
Fig. 3. A model of the relationships among science, managers of Atlantic salmon, and other interested groups of people. The ellipse represents a lens that focusses on values important to interest groups. NGOs is a term for non-government organizations.

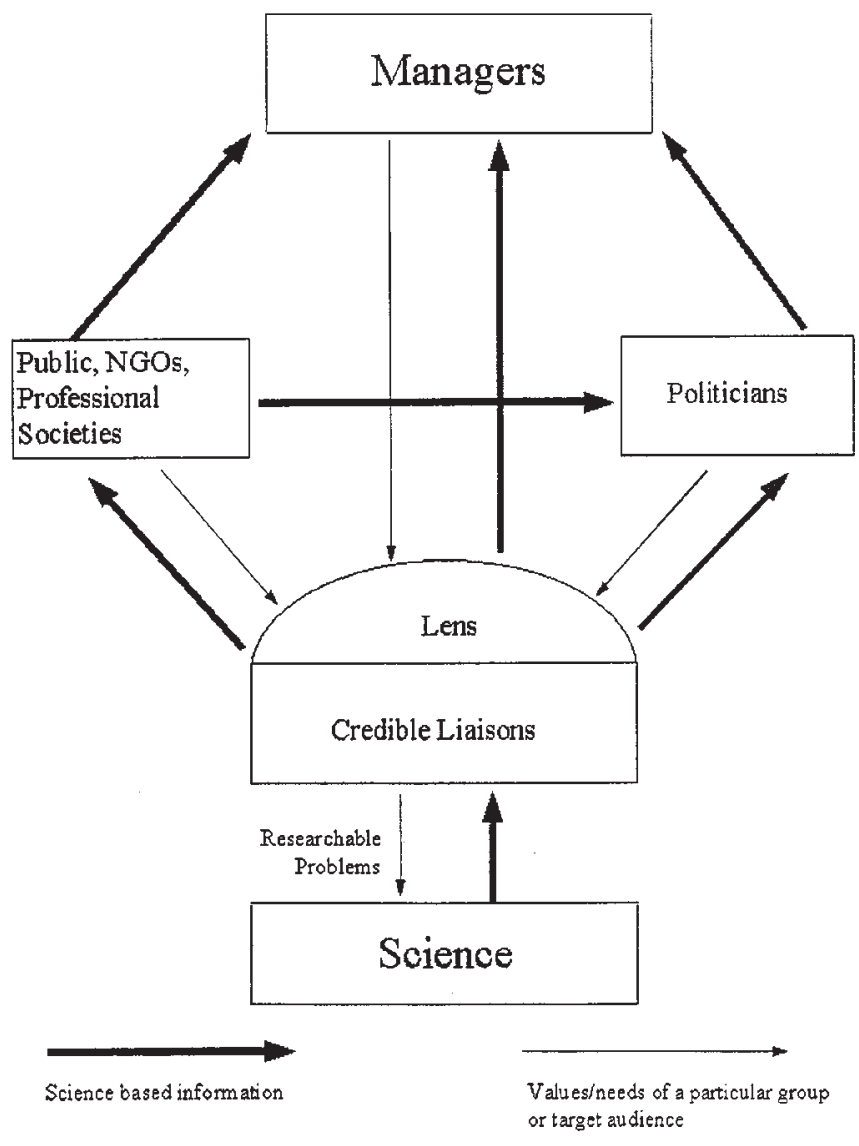

represented by politicians, non-governmental organizations (e.g., conservation groups, sport/commercial fishing industry groups, professional societies), and the public at large.

Not evident in the diagram are other factors that contribute to the acceptance and use of science. In some cases the use of "best science information" is mandated by law (e.g., the United States' Endangered Species and National Environmental Policy Acts). More often than not use is facilitated by actions of enlightened scientists and managers, where effective working relationships are based on mutual respect, integrity, and honesty. Recognizing, communicating, and celebrating the benefits of successful application of science findings helps to reinforce and perpetuate the practice.

\section{Concluding remarks}

Hierarchies of scale can be useful concepts, when coupled with hierarchies of the processes that influence production, in developing strategies for managing Atlantic salmon. In broad terms, it is important to integrate across scales in considering the management of salmon. However, depending on what factor(s) limit(s) production on a particular system it may be appropriate to focus management actions at one particular scale or over limited ranges of scales.
Because of the complexities of the ecology of salmon and the geomorphology of river systems, there are not yet clear, unifying, science-based models available to managers. Instead, each river system should be considered independently. Consequently, it is essential that managers are well-educated and informed, have good analytical and observational abilities, and have a sufficiently high level of support facilities. Managers also need good access to scientific research that will provide new insights. Integration between managers operating at different scales (e.g., central Government and local land owner) is particularly important on those rivers where there is a need to consider a wide range of scales.

We have outlined some of the general requirements of managers of salmon, the general processes that impinge on production of anadromous salmon and some aspects of how science has started to provide critical information for supporting good management. We have also noted how our current understanding of the biology of salmon is inadequate and have highlighted some specific areas where a better understanding could usefully be developed. We have also noted that a first requirement for applying science to management is to focus on the key issues that may be considered to be priorities. To help focus the integration of studies of salmon at different scales on some of these key areas, we strongly advocate work to develop:

(1) estimates of the productive capacities of systems integrating realistic life history, fish behavior, and habitat models;

(2) a detailed understanding of where, when, and on what scale bottlenecks in production occur in different types of system and what the shortfall is between achieved production and the capacity of the system should successive bottlenecks be removed;

(3) realistic estimates of the capacity for and costs and benefits of manipulating systems to enhance salmon fisheries and conserve stocks.

\section{Acknowledgments}

We thank the organizers, especially Martha Mather, Robert Lewis, Keith Jensen, Carol Folt, and Donna Parrish, of the workshop entitled "Integrating across scales: predicting patterns of change in Atlantic salmon," which stimulated the production of this manuscript. We also thank reviewers, both for comments at the workshop and on the manuscript.

\section{References}

Allen, K.R. 1969. Limitations on production in salmonid populations in streams. In Symposium on salmon and trout in streams. Edited by T.G. Northcote. University of British Columbia, Vancouver, B.C. pp. 3-18.

Armstrong, J.D. 1997. Self-thinning in juvenile salmonid fishes revisited. J. Anim. Ecol. 66: 519-526.

Armstrong, J.D., Shackley, P.E., and Gardiner, R. 1994. Redistribution of juvenile salmonid fishes after localised catastrophic depletion. J. Fish Biol. 45: 1027-1039.

Armstrong, J.D., Rycroft, P., and Braithwaite, V.A.1996. A passive integrated transponder detector array for monitoring movements of Atlantic salmon parr and other fish. J. Fish Biol. 48: 534 541. 
Armstrong, J.D., Braithwaite, V.A., and Huntingford, F.A. 1997. Spatial strategies of wild Atlantic salmon parr: exploration and settlement in unfamiliar areas. J. Anim. Ecol. 66: 203-211.

Armstrong, J.D., Braithwaite, V.A., and Fox, M. 1998. The response of wild Atlantic salmon parr to acute reductions in water flow. J. Anim. Ecol. 67: 292-297.

Bakke, T.A., and Harris, P.D. 1998. Disaeases and parasites in wild Atlantic salmon (Salmo salar) populations. Can. J. Fish. Aquat. Sci. 55:(Suppl. 1): 247-266.

Beland, K.F., Jordan, R.M., and Meister, A.L. 1982. Water depth and velocity preferences of spawning Atlantic salmon in Maine rivers. N. Am. J. Fish. Manage. 2: 11-13.

Beverton, R.J.H., and Holt, S.J. 1959. A review of the lifespan and mortality rates of fish in nature, and their relation to growth and other physiological characteristics. In The Lifespan of Animals. CIBA Foundation Symposium. pp. 142-180

Braithwaite, V.A., Armstrong, J.D., McAdam, H.M., and Huntingford, F.A. 1996. Can juvenile Atlantic salmon use multiple cue systems in spatial learning? Anim. Behav. 51: 1409-1415.

Cunjak, R.A. 1996. Winter habitat of selected stream fishes and potential impacts from land-use activity. Can. J. Fish. Aquat. Sci. 53(Suppl. 1): 267-282.

Cunjak, R.A., Prowse, T.D., and Parrish, D.L. 1998. Atlantic salmon (Salmo salar) in winter: "the season of parr discontent"? Can. J. Fish. Aquat. Sci. 55:(Suppl. 1): 161-180.

Elliott, J.M. 1994. Quantitative ecology and the brown trout. Oxford University Press, Oxford.

Elliott, S.R., Coe, T.A., Helfield, J.M., and Naiman, R.J. 1998. Atlantic salmon rivers: geomorphology, ecology and human impacts.

Erkinaro, J. 1995. The age structure and distribution of Atlantic salmon parr, Salmo salar L., in small tributaries and main stems of the subartic River Teno, southern Finland. Ecol. of Freshwater Fish, 4: 53-61.

Fausch, K.D. 1998. Interspecific competition and juvenile Atlantic salmon (Salmo salar): on testing effects and evaluating the evidence across scales. Can. J. Fish. Aquat. Sci. 55:(Suppl. 1): 218-231.

Fausch, K.D., Hawkes, C.L., and Parsons, M.B. 1988. Models that predict standing crops of stream fish from habitat variables: 1950-85. USDA For. Serv. Gen. Tech. Rep. WO-213.

Fleming, I.A. 1996. Reproductive strategies of Atlantic salmon: ecology and evolution. Rev. Fish Biol. Fish. 6: 379-416.

Fleming, I.A. 1998. Pattern and variability in the breeding system of Atlantic salmon (Salmo salar), with comparisons to other salmonids. Can. J. Fish. Aquat. Sci. 55:(Suppl. 1): 59-76.

Folt, C.L., Nislow, K.H., and Power, M.E. 1998. Implications of temporal and spatial scale for Atlantic salmon (Salmo salar) research. Can. J. Fish. Aquat. Sci. 55:(Suppl. 1): 9-21.

Friedland, K.D. 1998. Ocean climate influences on critical Atlantic salmon (Salmo salar) life history events. Can. J. Fish. Aquat. Sci. 55:(Suppl. 1): 119-130.

Frissell, C.A., Liss, W.J., Warren, C.E., and Hurley, M.D. 1986. A hierarchical framework for stream habitat classification: viewing streams in a watershed context. Environ. Manage. 10: 199-214.

Gibson, R.J. 1993. The Atlantic salmon in fresh water: spawning, rearing and production. Rev. Fish Biol. Fish. 3: 39-73.

Gowan, C., Young, M.K., Fausch, K.D., and Riley, S.C. 1994. Restricted movement in resident stream salmonids: a paradigm lost? Can. J. Fish. Aquat. Sci. 51: 2626-2637.

Grant, J.W.A., and Kramer, D.L. 1990. Territory size as a predictor of the upper limit to population density of juvenile salmonids in streams. Can. J. Fish. Aquat. Sci. 47: 1724-1737.
Grant, J.W.A., Steingrimsson, S.Ó., Keeley, E.R., and Cunjak, R.A. 1998. Implications of territory size for the measurement and prediction of salmonid abundance in streams. Can. J. Fish. Aquat. Sci. 55:(Suppl. 1): 181-190.

Gross, M.R. 1998. One species with two biologies: Atlantic salmon (Salmo salar) in the wild and in aquaculture. Can. J. Fish. Aquat. Sci. 55:(Suppl. 1): 131-144.

Gustafson-Greenwood, K.I., and Moring, J.R. 1990. Territory size and distribution of newly emerged Atlantic salmon (Salmo salar). Hydrobiologia, 206: 125-131.

Heggenes, J. 1990. Habitat utilization and preferences in juvenile Atlantic salmon (Salmo salar) in streams. Regul. Rivers Res. Manage. 5: 341-345.

Heggenes, J., Krog, O.M.W., Lindås, O.R., Dokk, J.G., and Bremnes, T. 1993. Homeostatic behavioural responses in a changing environment: brown trout (Salmo trutta) become nocturnal during winter. J. Anim. Ecol. 62: 295-308.

Hutchings, J.A., and Jones, M.E.B. 1998. Life history variation and growth rate thresholds for maturity in Atlantic salmon, Salmo salar. Can. J. Fish. Aquat. Sci. 55:(Suppl. 1): 22-47.

Imhof, J.G., Fitzgibbon, J., and Annable, W.K. 1996. A hierarchical eveluation system for characterizing watershed ecosystems for fish habitat. Can. J. Fish. Aquat. Sci. 53(Suppl. 1): 312-326.

Jonsson, B., and Jonsson, N. 1993. Partial migration: nich shift versus sexual maturation in fishes. Rev. Fish Biol. Fish. 3: 384 365.

Jonsson, N., Jonsson, B., and Fleming, I.A. 1996. Does early growth cause a phenotypically plastic response in egg production of Atlantic salmon? Funct. Ecol. 10: 89-96.

Lee, K.N. 1993. Compass and gyroscope: inegrating science and politics for the environment. Island Press, Washington, D.C.

Lewis, C.A., Lester, N.P., Bradshaw, A.D., Fitzgibbon, J.E., Fuller, K., Hakanson, L., and Richards, C. 1996. Considerations of scale in habitat conservation and restoration. Can. J. Fish. Aquat. Sci. 53(Suppl. 1): 440-445.

Mason, J.C. 1978. Response of underyearling coho salmon to supplemental feeding in a natural stream. J. Wildl. Manage. 40: 775-788.

Mather, M.E. 1998. The role of context-specific predation in predicting patterns exhibited by anadromous salmon. Can. J. Fish. Aquat. Sci. 55:(Suppl. 1): 232-246.

McCormick, S.D., Hansen, L.P., Quinn, T.P., and Saunders, R.L. 1998. Movement, migration and smolting of Atlantic salmon (Salmo salar). Can. J. Fish. Aquat. Sci. 55:(Suppl. 1): 77-92.

Metcalfe, N.B. 1998. The interaction between behaviour and physiology in determining life history patterns in Atlantic salmon (Salmo salar). Can. J. Fish. Aquat. Sci. 55:(Suppl. 1): 93-103.

Metcalfe, N.B., Taylor, A.C., and Thorpe, J.E. 1995. Metabolic rate, social status and life history strategies in Atlantic salmon. Anim. Behav. 49: 431-436.

Naiman, R.J., Magnuson, J.J., McKnight, D.M., and Stanford 1995. The freshwater imperative: a research agenda. Island Press, Washington, D.C.

Nielsen, J.L. 1998. Population genetics and the conservation and management of Atlantic salmon (Salmo salar). Can. J. Fish. Aquat. Sci. 55:(Suppl. 1): 145-152.

Poff, N.L., and Huryn, A.D. 1998. Multi-scale determinants of secondary production in Atlantic salmon (Salmo salar) streams. Can. J. Fish. Aquat. Sci. 55:(Suppl. 1): 201-217.

Prentice, E.F., Flagg, T.A., and McCutcheon, C.S. (1990). Feasibility of using implantable passive integrated transponder (PIT) tags in salmonids. Am. Fish. Soc. Symp. 7: 317-322.

Quinn, T.P., and Dittman, A.H. 1992. Fishes. In Animal homing. Edited by F. Papi. Chapman \& Hall, London. pp. 145-212. 
Rabeni, C.F., and Sowa, S.P. 1996. Intergrating biological realism into habitat restoration and conservation strategies. Can. J. Fish. Aquat. Sci. 53(Suppl. 1): 252-259.

Schlosser, I.J., and P.L. Angermeier. 1995. Spatial variation in demographic processes of lotic fishes: conceptual models, empirical evidence, and implications for conservation. Am. Fish. Soc. Symp. 17: 392-401.

Shearer, W.M. 1990. The Atlantic salmon: natural history, exploitation and future management. Fishing News Books, London.

Stradmeyer, L., and Thorpre, J.E. 1987. Feeding behaviour of wild Atlantic salmon Salmo salar L., parr in mid- to late-summer in a Scottish river. Aquacult. Fish. Manage. 18: 33-49.
Welcomme, R.L. 1992. A history of international introductions of inland aquatic species. ICES Mar. Sci. Symp. 194: 3-14.

Wheeler, A., and Maitland, P.S. 1973. The scarcer freshwater fishes of the British Isles: I. Introduced species. J. Fish. Biol. 5: 49-68.

White, R.J. 1996. Growth and development of North American stream habitat management for fish. Can. J. Fish. Aquat. Sci. 53(Suppl. 1): 342-363.

Youngson, A.F., and Verspoor, E. 1998. Interactions between wild and introduced Atlantic salmon (Salmo salar). Can. J. Fish. Aquat. Sci. 55:(Suppl. 1): 153-160. 